\title{
Primary malignant melanoma of the ascending colon
}

\author{
Spyridon Miliaras, ${ }^{1}$ Ioannis A Ziogas, ${ }^{2}$ Konstantinos S Mylonas, ${ }^{3}$ \\ Vasileios N Papadopoulos ${ }^{1}$
}

${ }^{1} 1$ st Department of Surgery, Papageorgiou University General Hospital, Aristotle University of Thessaloniki School of Medicine, Thessaloniki, Greece

${ }^{2}$ Aristotle University of Thessaloniki School of Medicine, Thessaloniki, Greece

${ }^{3}$ Division of Pediatric Surgery, Massachusetts General Hospital, Boston, Massachusetts, USA

\section{Correspondence to} Dr Konstantinos S Mylonas, ksmylonas@sni.gr

Accepted 26 January 2018

\section{SUMMARY}

Malignant gastrointestinal melanoma is usually a metastatic lesion. We report the case of a 67-yearold female patient who presented with intermittent abdominal pain, fever, rigor and diarrhoea. CT scan of the abdomen revealed a large mass at the right iliac fossa with features concerning for intraabdominal abscess. Exploratory laparotomy confirmed the preoperative diagnosis of abscess, and a right hemicolectomy was performed. Histopathological examination of the surgical specimen was indicative of malignant melanoma, and immunohistochemical examination showed positivity to $S 100$ protein, Melan- $A$, HMB-45 and vimentin. A series of postoperative clinical, laboratory and imaging examinations revealed no suspicious lesions in the skin, eye, leptomeninges or other sites. Therefore, the diagnosis of primary colonic melanoma was confirmed. Only 36 additional cases of primary colonic melanoma have been reported to date. These rare neoplasms are challenging to diagnose and usually require a multidisciplinary treatment approach, including surgery, chemotherapy and possibly immunotherapy or radiotherapy.

\section{BACKGROUND}

Melanoma is a group of tumours that develop from the malignant transformation of melanocytes. Even though it mainly affects the skin, melanoma can also present extracutaneously (eg, on the uvea, leptomeninges or mucous membranes). ${ }^{1}$ Melanomas of the gastrointestinal (GI) tract are rare, account for $1 \%-3 \%$ of the total malignant tumours of the digestive system, but constitute the most common tumours that metastasise to the GI tract. ${ }^{2}$ Metastatic melanoma of the GI tract mostly affects the liver (68\%), small intestine (58\%), colon $(22 \%)$ and stomach (20\%), and less frequently the duodenum (12\%), rectum (5\%), oesophagus (4\%) and anus $(1 \%){ }^{3}$

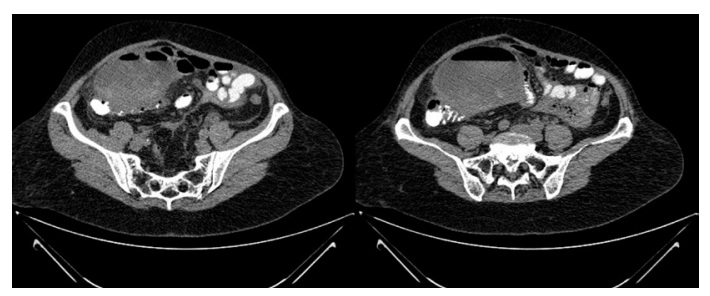

Mylonas KS, et al. BMJ Case Rep Published Online First: [please include Day Month Year]. doi:10.1136/bcr-2017223282

Check for updates
Figure 1 CT scan of the abdomen: a sizeable mass in the right iliac fossa mostly compatible with an intraabdominal abscess.
Primary malignant melanomas of the GI tract are much rarer than metastatic lesions. Primary melanomas may arise in any site of the GI tract, such as the anorectal region (anus $31.4 \%$ and rectum $22.2 \%)$, pharyngeal cavity (32.8\%), oesophagus $(5.9 \%)$, stomach $(2.7 \%)$, small intestine $(2.3 \%)$, gallbladder (1.4\%) and large intestine $(0.9 \%){ }^{4}$

Here we report the case of a female patient with malignant melanoma of the ascending colon and review available literature on melanoma of the GI tract.

\section{CASE PRESENTATION}

A 67-year-old female patient was admitted to the emergency department with a history of fever (up to $39^{\circ} \mathrm{C}$ ), rigor, intermittent hypogastric pain and diarrhoea for the past 2 weeks.

Her medical history was significant for osteoporosis, and her family history was unremarkable. On physical examination, the patient presented with fever, mild tachycardia, and normal blood pressure and cardiopulmonary examination. The abdomen was soft, with mild tenderness at the right iliac fossa, audible bowel sounds and absence of organomegaly or any palpable intra-abdominal mass.

\section{INVESTIGATIONS}

Rectal examination was also unremarkable. Leucocytosis (white cell count $26.29 \times 10^{9} / \mathrm{L}$ ), mild anaemia (haemoglobin: $10.8 \mathrm{~g} / \mathrm{dL}$, haematocrit: $34.0 \%$ ) and elevation of the $\mathrm{C}$ reactive protein $(21.80 \mathrm{mg} / \mathrm{dL})$ were also found.

CT scan of the abdomen was suggestive of a sizeable intra-abdominal abscess located at the right lower quadrant (figure 1). Given that the initial clinical impression was possible perforation of an ascending colon diverticulum, we proceeded with an emergent exploratory laparotomy. The presence of an abscess in relation to the ascending colon was confirmed intraoperatively, and a right hemicolectomy was performed.

Gross examination showed a grey-brown, soft, polypoid tumour with a maximum diameter of $4 \mathrm{~cm}$ located medially to the right colon. Histologically, the tumour was composed of medium to large sized cells with prominent nucleoli, eosinophilic cytoplasm and focal pigmentation, arranged in solid sheets (figure 2). The neoplasm infiltrated the surrounding connective tissue, but no necrosis, angiolymphatic or perineural invasion was found. The specimen also included reactive but not metastatic regional lymph nodes, and the surgical margins were free of neoplastic 


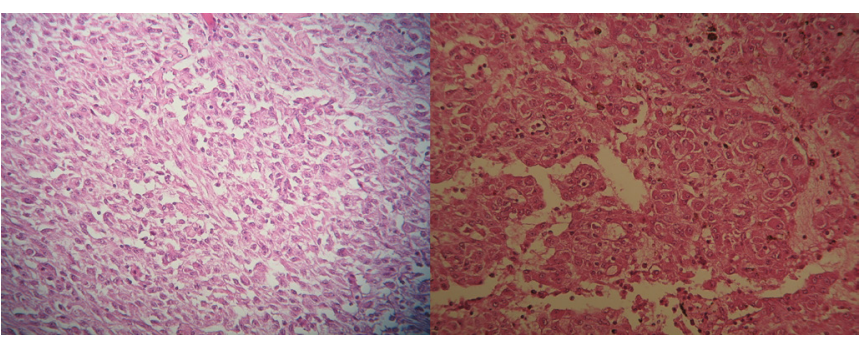

Figure 2 Epithelioid melanoma cells with prominent nucleoli (Hematoxylin \& Eosin (H\&E) stain) (x400).

infiltrations. Immunohistochemical staining of the neoplasm showed that the tumour cells were positive to S100 protein (figure 3), Melan-A (figure 4), $\mathrm{HMB}-45$ (figure 5) and vimentin, but negative to CK-7, SMA, LCA, c-kit (CD117), AE1/AE3 and CD138. These histological findings were compatible with the diagnosis of an ascending colon malignant melanoma.

Considering that most GI tract melanomas are metastatic lesions, the patient was subjected to a series of clinical, laboratory and imaging examinations to possibly identify an underlying primary melanoma (eg, a dermal, ocular or mucosal tumour). A multidisciplinary team of providers, including dermatologists, ophthalmologists, gynaecologists, urologists, otolaryngologists and gastroenterologists, was involved in the care of the patient. All performed investigations were unremarkable, and according to the patient there was no relevant medical or family history of melanoma. No nevus or other clinically suspicious melachromatic skin lesion had been excised in the past either. Brain MRI and CT scan of the brain-neck-thorax, upper/lower abdomen and retroperitoneum revealed no concerning lesions.

\section{TREATMENT}

The patient was negative for V600 mutation of the BRAF gene, and mutations of the c-kit gene (exons 9,11, 13 and 17). Therefore, no BRAF or c-kit inhibitors (imatinib) were administered. The patient is since being treated with adjuvant chemotherapy, consisting of dacarbazine and cisplatin.

\section{OUTCOME AND FOLLOW-UP}

The patient is disease-free at 3 years of follow-up.

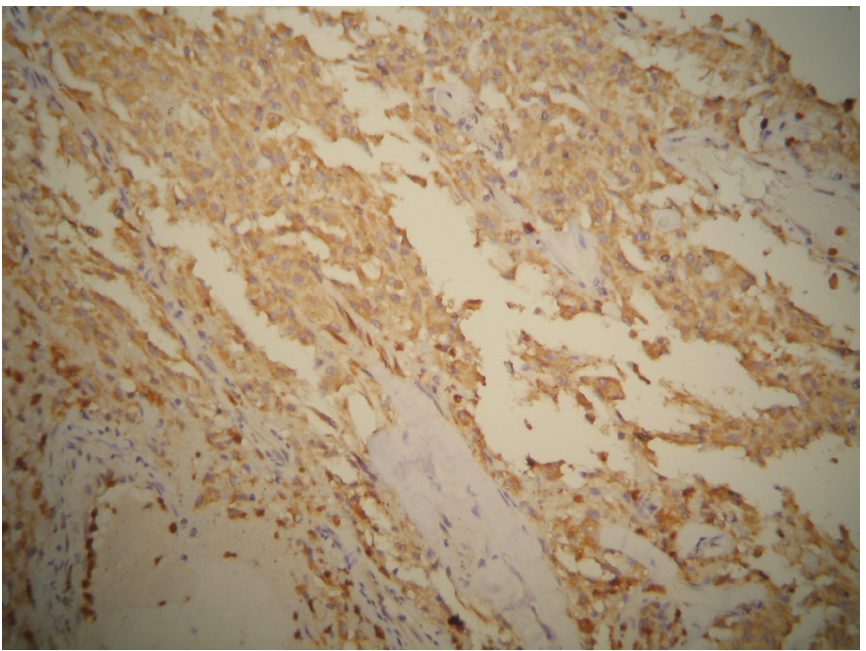

Figure 3 Cytoplasmic staining of malignant cells, S100 (x200).

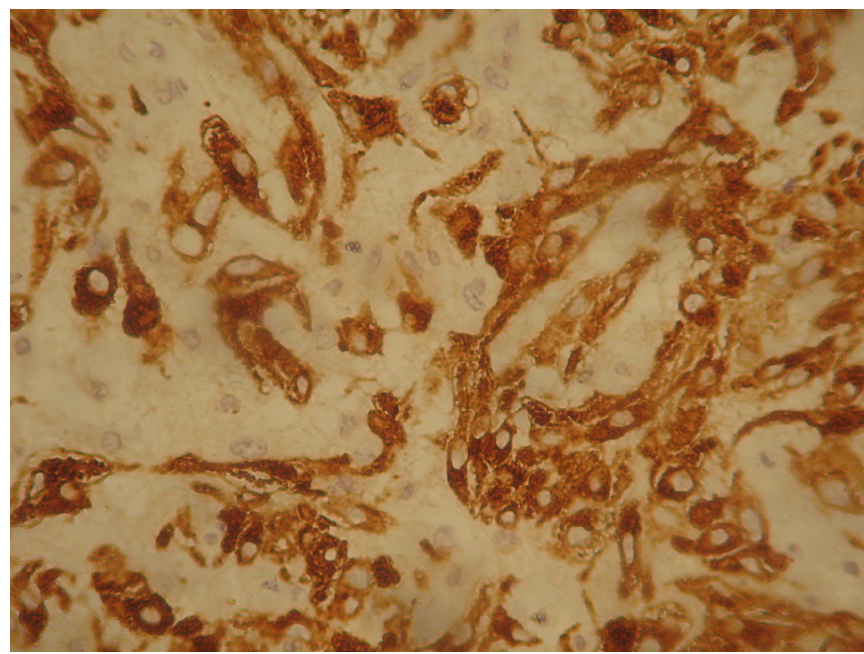

Figure 4 Cytoplasmic staining of melanoma cells, Melan-A (x400).

\section{DISCUSSION}

Primary melanoma of the GI tract is rare. Appreciating the presence of melanocytes in the oesophagus, stomach, small intestine, rectum and anus is central to understanding the development of melanoma in these sites. ${ }^{5-7}$ On the other hand, the pathogenesis of melanoma in the colon is less clear. In this study, we present a case of a 67-year-old patient with primary colonic melanoma and review relevant literature to summarise the epidemiology, management and outcomes of these uncommon GI malignancies.

Several theories have been proposed to explain the pathogenesis of primary colonic melanoma. The 'tumour regression theory' suggests that colonic melanomas could be metastatic lesions (synchronous or asynchronous) originating either from an undiagnosed primary skin tumour or a lesion that has undergone spontaneous regression. ${ }^{5-10}$ Histological examination is central in differentiating metastatic from primary melanoma with the former usually exhibiting lymphocytic infiltration of the dermis with melanophages, vascular proliferation, absence of malignant melanocytes and reactive fibrosis. ${ }^{11}$ In situ changes both in overlying and contiguous epithelial layers of the alimentary canal, atypical melanocytes in the basal layer and 'pagetoid' tumour cell expansion in the superficial epithelium are usually indicative of primary melanomas. ${ }^{10}$ The 'ectodermal differentiation theory' suggests that neural crest cells migrating to the

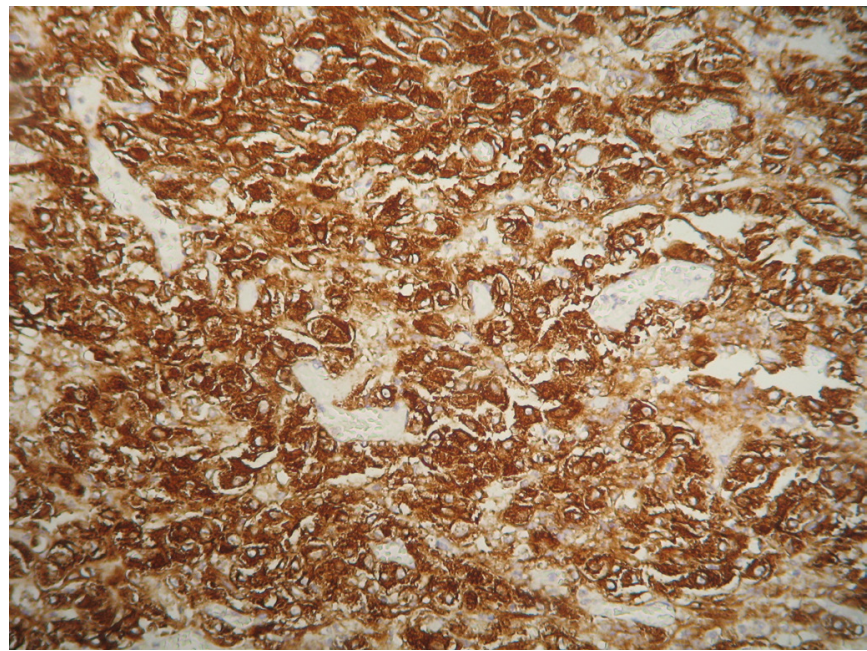

Figure 5 Cytoplasmic staining of malignant cells, HMB-45 (x400). 
Table 1 Review of published cases of primary malignant colonic melanoma

\begin{tabular}{|c|c|c|c|c|c|c|}
\hline Author & $\begin{array}{l}\text { Number of } \\
\text { patients }\end{array}$ & Sex/age & $\begin{array}{l}\text { Tumour size } \\
(\mathrm{cm})\end{array}$ & Tumour site & $\begin{array}{l}\text { Melan-A/ } \\
\text { S100/HMB-45 }\end{array}$ & Year of publication \\
\hline Poggi et al ${ }^{25}$ & 1 & $\mathrm{M} / 79$ & 8 & Right colon & $? /+/+$ & 2000 \\
\hline Avital et $a l^{26}$ & 1 & $\mathrm{M} / 41$ & 6.5 & Right colon & $+1-1+$ & 2004 \\
\hline Venkataraman et $a^{27}$ & 1 & $\mathrm{M} / 59$ & $?$ & Left colon & $? /+/ ?$ & 2004 \\
\hline McNicol and Jones ${ }^{28}$ & 1 & $\mathrm{M} / 84$ & $?$ & Caecum & $? /+/+$ & 2005 \\
\hline $\mathrm{Tak}^{29}$ & 1 & $\mathrm{M} / 72$ & $?$ & Transverse colon & $? /+1+$ & 2006 \\
\hline Mori et $\left.a\right|^{30}$ & 1 & $\mathrm{~F} / 88$ & 5 & Left colon & $+/+/+$ & 2006 \\
\hline Mandot et $a^{\beta 1}$ & 1 & $\mathrm{~F} / 62$ & $?$ & Right colon & $? /+1-$ & 2006 \\
\hline De Palma and Persico ${ }^{32}$ & 1 & $\mathrm{~F} / 56$ & $?$ & Right colon & $? /+/+$ & 2007 \\
\hline Takahashi-Monroy et a $\left.\right|^{33}$ & 1 & $F / 51$ & 4.2 & Caecum & $+/ ? /+$ & 2006 \\
\hline Kenney et $a l^{8}$ & 1 & $\mathrm{M} / 64$ & 5.5 & Transverse colon & $+/+1-$ & 2007 \\
\hline Sashiyama et $\left.a\right|^{34}$ & 1 & $F / 39$ & 2 & Caecum & $? / ? /+$ & 2010 \\
\hline Serin et $a l^{6}$ & 1 & $\mathrm{M} / 30$ & 14 & Caecum & $+/+/+$ & 2010 \\
\hline Busuttil et $a^{\beta 5}$ & 1 & $\mathrm{~F} / 73$ & 11 & Right colon & $+/+/+$ & 2013 \\
\hline Li et $a \beta^{36}$ & 1 & $M / 57$ & 4 & Right colon & $? /+/+$ & 2014 \\
\hline Furudoi et $a^{37}$ & 1 & $\mathrm{M} / 65$ & 3 & Right colon & $+/ ? / ?$ & 2016 \\
\hline
\end{tabular}

+: positive; -: negative; ?: not available.

Surgical resection is the mainstay of treatment for both primary and metastatic melanoma, regardless of site. Colonic melanoma is usually treated with colectomy followed by lymphadenectomy to achieve radical tumour resection with wide surgical margins. Infiltration depth, disease stage, patient age and lymph node status are the most significant determinants of prognosis. Patients presenting at an advanced disease stage, with positive lymph nodes and unresectable tumours usually have poor prognosis. ${ }^{35} 38$ Most patients also receive adjuvant chemotherapy, radiotherapy (in case of brain metastases) and possibly immunotherapy. Although melanomas are chemotherapy-resistant tumours, approximately $25 \%$ of the patients seem to respond to treatment with regimens including dacarbazine with or without cisplatin. ${ }^{539}$ Immunotherapy with c-kit (imatinib) and BRAF inhibitors (vemurafenib, sorafenib, PLX-4032, GSK2118436) is reserved for tumours with c-kit amplifications and BRAF mutations, respectively. ${ }^{40-44}$

colon from the caudal branchial arches may differentiate into mature pigment cells holding the potential to generate melanoma. Although the ectodermal differentiation theory has been validated in vitro, it has still to be proven in vivo. ${ }^{12}$ Melanocytes and amine precursor uptake and decarboxylation cells may also migrate to the terminal ileum through the omphalomesenteric duct acting as another potential source of primary malignant melanoma. ${ }^{1314}$ Migration of anal melanocytes and heterotopic melanocyte growth from primordial stem cells are possible pathogenetic mechanisms for the development of melanoma in the colon as well. ${ }^{1516}$

Considering that no criteria have been devised to help diagnose primary colonic melanoma, we opted to follow recommendations used for other mucosal melanomas. Particularly, our patient's tumour fulfilled five out of the six clinical criteria used to diagnose bronchial mucosal melanoma, including (1) solitary lesion in the surgical specimen, (2) absence of history of resection of skin tumour or other suspicious lesion, (3) absence of ocular tumour history, (4) morphology compatible with a primary tumour and (5) absence of a synchronous melanoma at the time of surgery. ${ }^{17}$ Our patient's tumour also fulfilled all three criteria used to diagnose intestinal melanoma: (1) solitary, histologically confirmed melanoma; (b) absence of disease in the skin, eye, distant lymph node infiltration or other distant metastasis; and (c) a minimum of 12-month disease-free survival from the time of diagnosis. ${ }^{18}$ That said, our patient has been followed for 3 years and has exhibited no sign of disease.

Our patient's tumour was CD117 negative and HMB-45, Melan-A and S100 protein positive. We ruled out a number of other tumours that may also stain positive for protein S100. All stromal tumours of the GI tract (GISTs) are CD117 positive, $10 \%$ are $\mathrm{S} 100$ protein positive with nearly $5 \%$ arising in the colon. Although 55\% of melanomas are also positive for CD117, ${ }^{19-23}$ our patient's tumour was CD117 negative, therefore ruling out GIST as a potential diagnosis. Clear cell sarcoma can also stain positive for $\mathrm{S} 100$ protein, but was considered it an unlikely diagnosis because of the absence of its cardinal histopathological findings (monotonous population, cells looking like osteoclasts). ${ }^{24}$ Another commonly S100 protein-positive tumour, neurofibrosarcoma, was also ruled out pathologically. Of note, neurofibrosarcomas exhibit a monotonous spindle cell pattern, with increased necrosis and vascularity, punched out nuclei and neoplastic cells assembled in the perivascular space. ${ }^{5}$

We identified only 36 cases of primary colonic melanoma in published literature ${ }^{6}$ 25-37 $^{25}$ (table 1). From an epidemiological standpoint, melanomas mostly develop in the ascending colon (46.7\%) and caecum (26.7\%) and less frequently in the transverse $(13.3 \%)$ and left colon (13.3\%). Based on available data, the male-to-female ratio is $3: 2$ ( 9 males vs six females), mean patient age is $61.3 \pm 16.6$ years, and mean tumour size is $6.3 \pm 3.7 \mathrm{~cm}$. Our literature search also suggests that abdominal pain and weight loss are the most common presenting clinical symptoms, with bleeding, neurological deficit and palpable abdominal being less frequently reported. ${ }^{5}$ Primary colonic melanoma may rarely

\section{Learning points}

- Gastrointestinal melanomas are rare and account for $1 \%-3 \%$ of the total malignancies of the digestive system, with the primary ones exhibiting even greater rarity.

- Diagnosis of intestinal melanoma requires fulfilment of the following criteria: (1) solitary, histologically confirmed melanoma; (2) absence of disease in the skin, eye, distant lymph node infiltration or other distant metastasis; and (3) a minimum of 12-month disease-free survival from the time of diagnosis.

- Treatment involves surgical resection and adjuvant therapy with immunotherapy (c-kit and BRAF inhibitors), chemotherapy (dacarbazine with or without cisplatin) and radiotherapy (for brain metastases). 
present as acute abdomen due to intestinal obstruction, intussusception or perforation (as in our patient). ${ }^{53336}$

Contributors Study concept and design, acquisition of data, analysis and interpretation of data, drafting of the manuscript, critical revision of the manuscript for important intellectual content and final approval of the version to be submitted: IAZ, SM, KSM, VNP.

Funding This research received no specific grant from any funding agency in the public, commercial or not-for-profit sectors.

\section{Competing interests None declared.}

Patient consent Obtained.

Provenance and peer review Not commissioned; externally peer reviewed. (c) BMJ Publishing Group Ltd (unless otherwise stated in the text of the article) 2018. All rights reserved. No commercial use is permitted unless otherwise expressly granted.

\section{REFERENCES}

1 Mihajlovic M, Vlajkovic S, Jovanovic $\mathrm{P}$, et al. Primary mucosal melanomas: a comprehensive review. Int J Clin Exp Pathol 2012;5:739-53.

2 Blecker D, Abraham S, Furth EE, et al. Melanoma in the gastrointestinal tract. Am J Gastroenterol 1999:94:3427-33.

3 Schuchter LM, Green R, Fraker D. Primary and metastatic diseases in malignant melanoma of the gastrointestinal tract. Curr Opin Oncol 2000;12:181-5.

4 Cheung MC, Perez EA, Molina MA, et al. Defining the role of surgery for primary gastrointestinal tract melanoma. J Gastrointest Surg 2008;12:731-8.

5 Khalid U, Saleem T, Imam AM, et al. Pathogenesis, diagnosis and management of primary melanoma of the colon. World J Surg Oncol 2011;9:14.

6 Serin G, Doganavsargil B, Caliskan C, et al. primary or metastatic? Case report. Turk J Gastroenterol 2010;21:45-9.

7 Tomioka K, Ojima H, Sohda M, et al. Primary malignant melanoma of the rectum: report of two cases. Case Rep Surg 2012;2012:1-4.

8 Kenney B, Dotto J, Homer R, et al. Primary malignant melanoma of the transverse colon: report of a case and review of the literature. Int J Surg Pathol 2007;15:401-7.

9 McGovern VJ. Spontaneous regression of melanoma. Pathology 1975;7:91-9.

10 Krishna Mohan MV, Rajappa SJ, Reddy TV, et al. Malignant gastrointestinal melanoma with an unknown primary. Indian J Med Paediatr Oncol 2009:30:87-9.

11 Bodurtha A. Spontaneous regression of malignant melanoma. In: Clark W, ed. Human malignant melanoma. New York: Grune and Stratton, 1979:227-41.

12 Jacobs-Cohen RJ, Wade PR, Gershon MD. Suppression of the melanogenic potential of migrating neural crest-derived cells by the branchial arches. Anat Rec 2002;268:16-26.

13 Li G, Tang X, He J, et al. Intestinal obstruction due to primary intestinal melanoma in a patient with a history of rectal cancer resectioning: A case report. Mol Clin Oncol 2014;2:233-6.

14 Amar A, Jougon J, Edouard A, et al. Primary malignant melanoma of the small intestine. Gastroenterol Clin Biol 1992;16:365-7.

15 Nicholson AG, Cox PM, Marks CG, et al. Primary malignant melanoma of the rectum. Histopathology 1993;22:261-4.

16 Hong SS, Min YI, Yang SK, et al. Melanosis of the colon and terminal ileum associated with primary malignant melanoma of the anorectum. Gastrointest Endosc 2006;63:886-8.

17 Ozdemir N, Cangir AK, Kutlay H, et al. Primary malignant melanoma of the lung in oculocutaneous albino patient. Eur J Cardiothorac Surg 2001:20:864-7.

18 Sachs DL, Lowe L, Chang AE, et al. Do primary small intestinal melanomas exist? Report of a case. J Am Acad Dermatol 1999;41:1042-4.
19 Hassan I, You YN, Dozois EJ, et al. Clinical, pathologic, and immunohistochemical characteristics of gastrointestinal stromal tumors of the colon and rectum: implications for surgical management and adjuvant therapies. Dis Colon Rectum 2006:49:609-15.

20 Miettinen M, Lasota J, tumors Gstromal. GISTs): definition, occurrence, pathology, differential diagnosis and molecular genetics. Pol J Pathol 2003:54:3-24.

21 Miettinen M, Sobin LH, Lasota J. Gastrointestinal stromal tumors of the stomach: a clinicopathologic, immunohistochemical, and molecular genetic study of 1765 cases with long-term follow-up. Am J Surg Pathol 2005;29:52-68.

22 Isabel Zhu Y, Fitzpatrick JE. Expression of c-kit (CD117) in Spitz nevus and malignant melanoma. J Cutan Pathol 2006:33:33-7.

23 Janku F, Novotny J, Julis I, et al. KIT receptor is expressed in more than $50 \%$ of earlystage malignant melanoma: a retrospective study of 261 patients. Melanoma Res 2005; 15:251-6.

24 WHO. Classification of Tumours. In: Fletcher CDM, Unni KK, eds. Pathology and Genetics of Tumors of Soft Tissue. Lyon: IARC Press, 2002:12-224.

25 Poggi SH, Madison JF, Hwu WJ, et al. Colonic melanoma, primary or regressed primary. J Clin Gastroenterol 2000;30:441-4.

26 Avital S, Romaguera RL, Sands L, et al. Primary malignant melanoma of the right colon. Am Surg 2004;70:649-51.

27 Venkataraman S, Peter S, Pulimood AB. Colonic malignant melanoma mimicking colon carcinoma. Digestive Endoscopy 2004;16:266-8.

$28 \mathrm{McNicol} F$, Jones LS. Primary malignant melanoma of the colon in an oculocutaneous albino. Surgeon 2005:3:358-9.

29 Tak AM. Metastatic melanoma: a case of unknown site of primary origin. Internet J Gastroenterol 2006.

30 Mori D, Satoh T, Nakafusa Y, et al. Primary colonic malignant melanoma. Pathol Int 2006;56:744-8.

31 Mandot A, Kazi K, Gupta T, et al. Primary malignant melanoma of right colon. Indian J Gastroenterol 2006:25:96-7.

32 De Palma GD, Persico G. Primary malignant melanoma of the right colon. Clin Gastroenterol Hepatol 2007;5:A28.

33 Takahashi-Monroy T, Vergara-Fernandez 0, Aviles A, et al. Primary melanoma of the colon presenting as ileocecal intussusception. Am J Gastroenterol 2006;101:676-7.

34 Sashiyama $\mathrm{H}$, Tsujinaka Y, Hamahata Y, et al. Primary amelanotic malignant melanoma of the colon. Endoscopy 2010;42:E163-4.

35 Busuttil G, Blazic I, Caruana DG, et al. Primary melanoma of the right colon presenting with gastrointestinal bleeding. Open Gastroenterology Journal 2013;1:1-3.

36 Li WX, Wei Y, Jiang Y, et al. Primary colonic melanoma presenting as ileocecal intussusception: case report and literature review. World J Gastroenterol 2014;20:9626-30

37 Furudoï A, Caumont C, Dutriaux C, et al. Primary digestive melanoma in association with tubular adenoma: a case report illustrating the distinction from metastatic colonic melanoma. Hum Pathol 2016:48:167-71.

$38 \mathrm{Kim}$ W, Baek JM, Suh YJ, et al. Ileal malignant melanoma presenting as a mass with aneurysmal dilatation: a case report. J Korean Med Sci 2004;19:297-301.

39 Yang AS, Chapman PB. The history and future of chemotherapy for melanoma. Hematol Oncol Clin North Am 2009:23:583-97.

40 Curtin JA, Busam K, Pinkel D, et al. Somatic activation of KIT in distinct subtypes of melanoma. J Clin Oncol 2006:24:4340-6.

41 Beadling C, Jacobson-Dunlop E, Hodi FS, et al. KIT gene mutations and copy number in melanoma subtypes. Clin Cancer Res 2008;14:6821-8.

42 Sullivan RJ, Flaherty KT. BRAF in Melanoma: pathogenesis, diagnosis, inhibition, and resistance. J Skin Cancer 2011;2011:1-8.

43 Safaee Ardekani G, Jafarnejad SM, Tan L, et al. The prognostic value of BRAF mutation in colorectal cancer and melanoma: a systematic review and meta-analysis. PLoS One 2012;7:e47054.

44 Sosman JA, Kim KB, Schuchter L, et al. Survival in BRAF V600-mutant advanced melanoma treated with vemurafenib. N Engl J Med 2012:366:707-14.

Copyright 2018 BMJ Publishing Group. All rights reserved. For permission to reuse any of this content visit http://group.bmj.com/group/rights-licensing/permissions.

BMJ Case Report Fellows may re-use this article for personal use and teaching without any further permission.

Become a Fellow of BMJ Case Reports today and you can:

- Submit as many cases as you like

- Enjoy fast sympathetic peer review and rapid publication of accepted articles

- Access all the published articles

- Re-use any of the published material for personal use and teaching without further permission

For information on Institutional Fellowships contact consortiasales@bmjgroup.com

Visit casereports.bmj.com for more articles like this and to become a Fellow 